\section{Scientific Presenting: Using Evidence- Based Classroom Practices to Deliver Effective Conference Presentations}

\author{
Lisa A. Corwin, ${ }^{\dagger}$ Amy Prunuske, ${ }^{\ddagger}$ and Shannon B. Seidel ${ }^{\S *}$ \\ ${ }^{\dagger}$ Department of Ecology \& Evolutionary Biology, University of Colorado, Boulder, Boulder, \\ CO 80309; :Department of Microbiology and Immunology, Medical College of Wisconsin- \\ Central Wisconsin, Wausau, WI 54401; 'Biology Department, Pacific Lutheran University, \\ Tacoma, WA 98447
}

\begin{abstract}
Scientists and educators travel great distances, spend significant time, and dedicate substantial financial resources to present at conferences. This highlights the value placed on conference interactions. Despite the importance of conferences, very little has been studied about what is learned from the presentations and how presenters can effectively achieve their goals. This essay identifies several challenges presenters face when giving conference presentations and discusses how presenters can use the tenets of scientific teaching to meet these challenges. We ask presenters the following questions: How do you engage the audience and promote learning during a presentation? How do you create an environment that is inclusive for all in attendance? How do you gather feedback from the professional community that will help to further advance your research? These questions target three broad goals that stem from the scientific teaching framework and that we propose are of great importance at conferences: learning, equity, and improvement. Using a backward design approach, we discuss how the lens of scientific teaching and the use of specific active-learning strategies can enhance presentations, improve their utility, and ensure that a presentation is broadly accessible to all audience members.
\end{abstract}

Attending a conference provides opportunities to share new discoveries, cutting-edge techniques, and inspiring research within a field of study. Yet after presenting at some conferences, you might leave feeling as though you did not connect with the audience, did not receive useful feedback, or are unsure of where you fit within the professional community. Deciding what to cover in a presentation may be daunting, and you may worry that the audience did not engage in your talk. Likewise, for audience members, the content of back-to-back talks may blur together, and they may get lost in acronyms or other unfamiliar jargon. Audience members who are introverted or new to the field may feel intimidated about asking a question in front of a large group containing wellknown, outspoken experts. After attending a conference, one may leave feeling curious and excited or exhausted and overwhelmed, wondering what was gained from presenting or attending.

Conferences vary widely in purpose and location, ranging from small conferences hosted within home institutions to large international conferences featuring experts from around the world. The time and money spent to host, attend, and present at conferences speaks to the value placed on engaging in these professional interactions. Despite the importance of conferences to professional life, there is rarely time to reflect on what presenters and other conference attendees learn from participating in conferences or how conferences promote engagement and equity in the field as a whole. A significant portion of most conference time is devoted to the delivery of oral presentations, which traditionally are delivered in a lecture style, with questions being initiated by a predictable few during question-and-answer sessions.
Michèle Shuster, Monitoring Editor Submitted August 1, 2017; Revised October 26, 2017; Accepted October 27, 2017

CBE Life Sci Educ March 1, 2018 17:es1 DOI:10.1187/cbe.17-07-0146

*Address correspondence to: Shannon B. Seidel (shannonseidel@gmail.com)

() 2018 L. A. Corwin et al. CBE-Life Sciences Education () 2018 The American Society for Cell Biology. This article is distributed by The American Society for Cell Biology under license from the author(s). It is available to the public under an Attribution-Noncommercial-Share Alike 3.0 Unported Creative Commons License (http://creativecommons.org/licenses/ by-nc-sa/3.0).

"ASCB ${ }^{\circledR "}$ and "The American Society for Cell Biology ${ }^{\circledR "}$ are registered trademarks of The American Society for Cell Biology. 
In this essay, we discuss how you can use a backward design approach and scientific presenting strategies to overcome three key challenges to effectively presenting to diverse conference audiences. The challenges we consider here include the following:

1. Engagement in learning: ensuring that your audience is engaged and retains what is important from a talk

2. Promoting equity: creating an environment that is inclusive of all members of the research field

3. Receiving feedback: gathering input from the professional community to improve as a researcher and presenter

At conferences, learning and advancement of a field is paramount, similar to more formal educational settings. Thus, we wrote these presenting challenges to align with the central themes presented in the scientific teaching framework developed by Handelsman and colleagues (2007). "Learning" aligns with "active learning," "equity" with "diversity," and "feedback" with "assessment." Using the scientific teaching framework and a backward design approach, we propose using evidence-based teaching strategies for scientific presenting in order to increase learning, equity, and quality feedback. We challenge you, the presenter, to consider how these strategies might benefit your future presentations.

\section{BACKWARD DESIGN YOUR PRESENTATION: GOALS AND AUDIENCE CONSIDERATIONS}

How will you define the central goals of your presentation and frame your presentation based on these goals? Begin with the end in mind by clearly defining your presentation goals before developing content and activities. This is not unlike the process of backward design used to plan effective learning experiences for students (McTighe and Thomas, 2003). Consider what you, as a presenter, want to accomplish. You may want to share results supporting a novel hypothesis that may impact the work of colleagues in your field or disseminate new techniques or methodologies that could be applied more broadly. You may seek feedback about an ongoing project. Also consider your audience and what you hope they will gain from attending. You may want to encourage your colleagues to think in new and different ways or to create an environment of collegiality. It is good to understand your audience's likely goals, interests, and professional identities before designing your presentation.

How can you get to know these important factors about your audience? Although it may not be possible to predict or know all aspects of your audience, identify sources of information you can access to learn more about them. Conference organizers, the website for the conference, and previous attendees may be good sources of information about who might be in attendance. Conference organizers may have demographic information about the institution types and career stages of the audience. The website for a conference or affiliated society often describes the mission of the organization or conference. Finally, speaking with individuals who have previously attended the conference may help you understand the culture and expectations of your audience. This information may enable you to tailor your talk and select strategies that will engage and resonate with audience members of diverse backgrounds. Most importantly, reflecting on the information you gather will allow you to evaluate and better define your presentation goals.
Before designing your presentation, write between two and five goals you have for yourself or your audience (see Vignettes 1 and 2 for sample goals). Prioritize your goals and evaluate which can be accomplished with the time, space, and audience constraints you face. Once you have established both your goals and knowledge of who might attend your talk, it is time to design your talk. The Scientific Presenting section that follows offers specific design suggestions to engage the audience in learning, promote equity, and receive high-quality feedback.

\section{SCIENTIFIC PRESENTING: USING A SCIENTIFIC TEACHING PERSPECTIVE TO DESIGN CONFERENCE PRESENTATIONS}

Presenters, like teachers, often try to help their audiences connect new information with what they already know (National Research Council, 2000). While a conference audience differs from a student audience, evidence and strategies collected from the learning sciences can assist in designing presentations to maximize learning and engagement. We propose that the scientific teaching framework, developed by Handelsman and colleagues (2007) to aid in instructional design, can be used as a tool in developing presentations that promote learning, are inclusive, and allow for the collection of useful feedback. In this section, we discuss the three pillars of scientific teaching: active learning, diversity, and assessment. We outline how they can be used to address the central challenges outlined earlier and

\section{VIGNETTE 1}

Situation: Mona Harrib has been asked to give the keynote presentation at a regional biology education research conference. As a leader in the field, Mona is well known and respected, and she has a good grasp on where the field has been and where it is going now.

Presentation Goals: She has three goals she wants to accomplish with her presentation: 1) to introduce her colleagues to the self-efficacy framework, 2) to provide new members of her field opportunities to learn about where the field has been, and 3) to connect these new individuals with others in the field.

Scientific Presenting Strategy: Mona has 50 minutes for her presentation, with 10 minutes for questions. Her opening slide, displayed as people enter the room, encourages audience members to "sit next to someone you have not yet spoken to." Because her talk will discuss self-efficacy theory and the various origins of students' confidence in their ability to do science, she begins by asking the audience members to introduce themselves to their neighbors and to describe an experience in which they felt efficacious or confident in their ability to do something and why they felt confident. She circulates around the room, and asks five groups to share their responses. This provides an audience-generated foundation that she uses to explain the framework in more detail. For historical perspective, she relates each framework component back to prior research in the field. She ends with some recent work from her research group and asks participants to discuss with their partners how the framework could be used to explain the results of her recent study. She again gathers and reports several examples to the whole group that illustrate ways in which the data might be interpreted. She then asks the audience to write a question that they still have about this research on note cards, which she collects and reviews after the presentation. After reviewing the cards, she decides to incorporate a little more explanation about a few graphs in her work to help future audiences digest the information. 


\section{VIGNETTE 2}

Situation: Antonio Villarreal is a postdoctoral fellow at the University of California, Berkeley, who has recently been selected for a 15-minute presentation in the Endocytic Trafficking Minisymposium at the American Society for Cell Biology Annual Meeting. He has attended this conference twice, so he has a sense of the audience, space, and culture of the meeting. In his past experiences, he has found that the talks often blur together, and it is especially difficult to remember key ideas from the later talks in each session.

Presentation Goals: With a manuscript in preparation and his upcoming search for a faculty position, Antonio has the following three goals for his presentation: 1) to highlight the significance of his research in a memorable way; 2) to keep the audience engaged, because his presentation is the ninth out of 10 talks; and 3) to receive feedback that will prepare him to give professional job talks.

Scientific Presenting Strategy: Antonio took a class as a postdoctoral fellow about evidence-based practices in teaching and decides he would like to incorporate some active learning into his talk to help his audience learn. He worries that with only 15 minutes he does not have a lot of time to spare. So he sets up the background and experimental design for the audience and then projects only the two axes of his most impactful graph on the screen with a question mark in the middle where the data would be. Rather than simply showing the result, he asks the audience to turn to a neighbor and make a prediction about the results they expect to see. He cues the audience to talk to one another by encouraging them to make a bold prediction! After 30 seconds, he quells the chatter and highlights two different predictions he heard from audience members before sharing the results. At the end of his presentation, he asks the audience to turn to a neighbor once again and discuss what the results mean and what experiment they would try next. He also invites them to talk further with him after the session. The questions Antonio receives after his talk are very interesting and help him consider alternative angles he could pursue or discuss during future talks. He also asks his colleague Jenna to record his talk on his iPhone, and he reviews this recording after the session to prepare him for the job market.

provide specific tips and strategies for applying scientific teaching in a conference setting.

\section{Challenge: Engagement in Learning}

Consider the last conference you attended: How engaged were you in the presentations? How many times did you check your phone or email? How much did you learn from the talks you attended? Professional communities are calling for more compelling presentations that convey information successfully to a broad audience (e.g., Carlson and Burdsall, 2014; Langin, 2017). Active-learning strategies, when combined with constructivist approaches, are one way to increase engagement, learning, and retention (Prince, 2004; Freeman et al., 2014). While active-learning strategies are not mutually exclusive with the use of PowerPoint presentations in the dissemination of information, they do require thoughtful design, time for reflection, and interaction to achieve deeper levels of learning (Chi and Wylie, 2014). This may be as simple as allowing 30-60 seconds for prediction or discussion in a 15-minute talk. On the basis of calls for change from conference goers and organizers and research on active-learning techniques, we have identified several potential benefits of active learning likely to enhance engagement in conference presentations:
1. Active learning increases engagement and enthusiasm. Active learning allows learners to maintain focus and enthusiasm throughout a learning experience (e.g., Michael, 2006). Use of active learning may particularly benefit audience members attending long presentations or sessions with back-to-back presenters.

2. Active learning improves retention of information. Active reflection and discussion with peers supports incorporation of information into one's own mental models and creates the connections required for long-term retention of information (reviewed in Prince, 2004).

3. Active learning allows for increased idea exchange among participants. Collaborative discourse among individuals with differing views enhances learning, promotes argumentation, and allows construction of new knowledge (Osborne, 2010). Active-learning approaches foster idea exchange and encourage interaction, allowing audience members to hear various perspectives from more individuals.

4. Active learning increases opportunities to build relationships and expand networks. Professional networking is important for expansion of professional communities, enhancing collaborations, and fostering idea exchange. Short collaborative activities during presentations can be leveraged to build social networks and foster community in a professional setting, similar to how they are used in instruction (Kember and Leung, 2005; Kuh et al., 2006).

While a multitude of ways to execute active learning exist, we offer a few specific suggestions to quickly engage the audience during a conference presentation (Table 1). In the spirit of backward design, we encourage you to identify learning activities that support attainment of your presentation goals. Some examples can be found in Vignettes 1 and 2 (section 1), which illustrate hypothetical scenarios in which active learning is incorporated into presentations at professional conferences to help meet specific goals.

Similar to giving a practice talk before the conference, we encourage you to test out active-learning strategies in advance, particularly if you plan to incorporate technology, because technological problems can result in disengagement (Hatch et al., 2005). Practicing presentation activities within a research group or local community will provide guidance on prompts, timing, instructions, and audience interpretation to identify problems and solutions before they occur during a presentation. This will help to avoid activities that are overly complex or not purpose driven (Andrew et al., 2011).

\section{Challenge: Equity and Participation}

Consider the last conference you attended: Did you hear differing opinions about your work or did the dominant paradigms prevail? Who asked questions; was it only high-status experts in the field? Did you hear from multiple voices? Did newer members, like graduate students and postdoctoral fellows, engage with established members of the community? In classroom settings, equity and diversity strategies improve learning among all students and particularly support students from underrepresented groups in science by decreasing feelings of exclusion, alleviating anxiety, and counteracting stereotype threat (Haak et al., 2011; Walton et al., 2012; Eddy and Hogan, 2014). Likewise, in a conference setting, strategies that promote equitable participation and 
TABLE 1. Active-learning strategies for conference presentations

\begin{tabular}{|c|c|c|}
\hline Strategy & Benefit & Facilitation tips \\
\hline $\begin{array}{l}\text { Think: Prompt audience members to reflect } \\
\text { individually. } \\
\text { Pair: Audience discusses prompt with a } \\
\text { neighbor. } \\
\text { Share: Individuals share an idea with the } \\
\text { entire audience. }\end{array}$ & $\begin{array}{l}\text { Audience members reflect, discuss, and } \\
\text { develop a topic. This brings in multiple } \\
\text { viewpoints and encourages participation } \\
\text { of many individuals. }\end{array}$ & $\begin{array}{l}\text { Think, pair, and share are listed separately, } \\
\text { because depending on time available, you } \\
\text { might do a think-pair, or a pair, or a pair- } \\
\text { share. To save time, you could eavesdrop } \\
\text { on conversations and share a couple of } \\
\text { ideas you heard from the groups rather } \\
\text { than having individuals share. }\end{array}$ \\
\hline $\begin{array}{l}\text { Make a prediction: After describing experi- } \\
\text { mental methodologies, have audience } \\
\text { members make a prediction about the } \\
\text { results before sharing. }\end{array}$ & $\begin{array}{l}\text { This engages the audience and familiarizes } \\
\text { them with expected outcomes before } \\
\text { sharing data. }\end{array}$ & $\begin{array}{l}\text { It may be useful to show a graph with a box } \\
\text { covering data to familiarize the audience } \\
\text { with the experimental framework and } \\
\text { scaffold their prediction. }\end{array}$ \\
\hline $\begin{array}{l}\text { Data interpretation: Show data and, rather } \\
\text { than explaining results immediately, allow } \\
\text { audience members to discuss and interpret. }\end{array}$ & $\begin{array}{l}\text { This supports better understanding of the } \\
\text { data, engages audience members, and } \\
\text { may benefit newer members of the } \\
\text { research community who are less familiar } \\
\text { with methodologies of the field. }\end{array}$ & $\begin{array}{l}\text { Use this strategy when data are complex or } \\
\text { busy. It may be helpful to structure this } \\
\text { with guiding questions to help the } \\
\text { audience focus (e.g., What trends do you } \\
\text { see? What do you think occurred at point } \\
\text { X?). }\end{array}$ \\
\hline $\begin{array}{l}\text { Electronic audience response: Prompt the } \\
\text { audience with a question and have them } \\
\text { respond in real time via an electronic } \\
\text { response system. }\end{array}$ & $\begin{array}{l}\text { This gives every individual in the audience } \\
\text { the chance to engage and share ideas } \\
\text { anonymously and can be a quick and } \\
\text { efficient way to get feedback from the } \\
\text { audience. }\end{array}$ & $\begin{array}{l}\text { Test this out in the space before the presenta- } \\
\text { tion if possible. Tailor your talk based on } \\
\text { feedback. Poll Everywhere allows creative } \\
\text { presentation of responses, e.g., in a word } \\
\text { cloud. Kahoot creates a game atmosphere. }\end{array}$ \\
\hline $\begin{array}{l}\text { Hand count or noise poll: Prompt the } \\
\text { audience to raise hands, stomp their feet, } \\
\text { snap their fingers, or clap if they agree with } \\
\text { your statement, have a common experi- } \\
\text { ence, etc. }\end{array}$ & $\begin{array}{l}\text { The benefits of this strategy are similar to } \\
\text { those of the digital version; however, there } \\
\text { is less of a risk with this polling method } \\
\text { because no digital tools are required. }\end{array}$ & $\begin{array}{l}\text { Encourage the audience to raise hands high if } \\
\text { it is low stakes. If the information you } \\
\text { seek is personal, you can have individuals } \\
\text { hold up a number of fingers near their } \\
\text { chest to hide votes from other audience } \\
\text { members. }\end{array}$ \\
\hline $\begin{array}{l}\text { Demonstrate use of a tool: Rather than talk } \\
\text { about a research tool or method, have } \\
\text { audience members try out the tool or proto- } \\
\text { col. }\end{array}$ & $\begin{array}{l}\text { This increases audience familiarity with the } \\
\text { tool and builds self-efficacy to implement } \\
\text { it. }\end{array}$ & $\begin{array}{l}\text { The experience may need to be shortened and } \\
\text { may require appropriate space and } \\
\text { materials. }\end{array}$ \\
\hline $\begin{array}{l}\text { Structure the Q\&A: Add a quick pair } \\
\text { discussion of the main point at the end of } \\
\text { the presentation. }\end{array}$ & $\begin{array}{l}\text { This creates processing time for the audience } \\
\text { to consider the take-home message and } \\
\text { may increase the diversity and quality of } \\
\text { questions. }\end{array}$ & $\begin{array}{l}\text { If this technique is new to the session, a quick } \\
\text { explanation of why you are using this } \\
\text { technique or quickly encouraging your } \\
\text { audience to think out loud may help get } \\
\text { things started. }\end{array}$ \\
\hline
\end{tabular}

recognize the positive impact of diversity in the field may help increase equity more broadly and promote a sense of belonging among participants. Conference audiences are oftentimes even more diverse than the typical classroom environment, being composed of individuals from different disciplines, career stages, and cultures. Incorporating strategies that increase the audience's understanding and feelings of inclusion in the professional community may impact whether or not an individual continues to engage in the field. We have identified three central benefits of equity strategies for presenters and their professional communities:

1. Equity strategies increase accessibility and learning. As a presenter, you should ensure that presentations and presentation materials 1) allow information to be accessed in various forms, so that differently abled individuals may participate fully, and 2) use straightforward language and representations. You can incorporate accessible versions of conference materials (e.g., captioned videos) or additional resources, such as definitions of commonly used jargon necessary to the presentation (e.g., Miller and Tanner, 2015).
You may consider defining jargon or acronyms in your talk to increase accessibility for individuals who might struggle to understand the full meaning (e.g., new language learners or individuals who are new to the field).

2. Equity strategies support inclusion of diverse views and priorities. Creating space for individuals from different backgrounds to express views on a topic supports critical evaluation of ideas and paradigms within a community and prevents members of the community from developing myopic or one-sided views on a subject. This helps to increase creative efforts and enhance new ideas that drive a community forward and sustain its growth (Richard and Shelor, 2002; Bassett-Jones, 2005). Furthermore, welcoming individuals from all backgrounds allows us to address relevant priorities for more populations and thus for our work to serve more communities (Hacker, 2013). These strategies can be accomplished by creating space for more individuals to participate in active-learning or question-and-answer sessions (e.g., asking for more hands; Table 2) or by deliberately using inclusive language as is recommended when teaching nonnative language learners 
TABLE 2. Equity strategies for conference presentations (as presented in Tanner, 2013)

Strategy
Wait time: Wait at least 5 seconds after posing
a question before asking for responses.
Multiple hands, multiple voices: Request
three hands in response to a question, and
wait for three people to raise their hands
before asking the first person to speak.

Work in small group/pairs: Engage participants in paired or small-group tasks.

Clearly state your intention for equity and inclusion: Verbally and through the use of presentation materials, inform your audience that you welcome and value diversity.

Do not judge responses: Work to acknowledge responses and ideas in a neutral manner that affirms participation.

Use inclusive language: Work to ensure that your language includes everyone in the room and does not exclude certain groups.

Explicitly encourage informal interaction: Provide messages that promote conversation and networking.
Collects multiple perspectives and views; gives more hesitant and thoughtful individuals a chance to participate

Removes the pressure of speaking in front of a large group and encourages all participants to have some degree of input; builds community

Highlights that equity is important for you as a member of the community and helps to builds the norm of equity and access into the conference setting

Creates a welcoming environment for members of the community who are at all levels of experience and learning

Ensures that groups who are often marginalized or excluded feel included in the conversation

Lowers the social barrier to make it easier for individuals to introduce themselves and start conversations with new people
Facilitation tips

Post the question on a slide or write it on a board so that individuals have time to process the information or encourage the audience to take 10 seconds to think about the posed question.

Inform the audience that you want to hear a variety of ideas from people who you have not heard from. Call on people in different parts of the room, particularly in the back. Phrase questions such that multiple perspectives are useful.

Be explicit with the audience: 1) the expectation that they will talk with one another, 2) the size of groups you prefer, 3) the amount of time they will have, and 4) the precise task. Encourage them to ensure all group members have a chance to speak. Encourage audience members to introduce themselves to those they do not know.

At the start of any activity, mention that you encourage and will strive for equitable participation in activities. For example, "We will do active learning and I value a diversity of opinions; I would like to hear from different people," or "I look forward to hearing a variety of thoughts during the question-and-answer session" can set a welcoming tone for the talk.

Reinforce the value of participating, saying, "Thank you for your thoughts," or some similar phrase. Actively recognize that diverse responses are valued: "We have received several ideas that will help us move forward."

Use terms that include all races or genders, such as "my friends" or "you all," in place of exclusionary terms like "you guys," which excludes women. Work to avoid colloquialisms that may not be understood by all or are exclusionary, such as "the best man for the job."

These messages may be in the form of written instructions on a slide or verbal instructions that encourage individuals to "meet someone new after the talk" or "sit next to someone you don't know."
(Motschenbacher, 2017) or serving patients in healthcare (e.g., Rossi and Lopez, 2017).

3. Equity strategies promote a sense of belonging among all individuals. Creating a welcoming, inclusive environment will make the community attractive to new members and help to increase community members' sense of belonging. Sense of belonging helps individuals in a community to view themselves as valued and important, which serves to motivate these individuals toward productive action. This increases positive affect, boosts overall community morale, and supports community development (Winter-Collins and
McDaniel, 2000). Belonging can increase if it is specifically emphasized as important and if individuals make personal connections to others, such as during small-group work (see Table 2).

Many strategies discussed in prior sections, such as using active learning and having clear goals, help to promote equity, belonging, and access. In Table 2, we expand on previously mentioned strategies and discuss how specific active-learning and equity strategies promote inclusiveness. These tips for facilitation are primarily drawn from Tanner's 2013 feature on classroom 
TABLE 3. Assessment and feedback strategies for conference presentations

\begin{tabular}{|c|c|c|}
\hline Strategy & Benefit & Facilitation tips \\
\hline $\begin{array}{l}\text { Audio or video recordings: Record full session } \\
\text { or participants engaged in activities. }\end{array}$ & $\begin{array}{l}\text { Provides an opportunity to review presenter } \\
\text { and audience behavior multiple times }\end{array}$ & $\begin{array}{l}\text { Inform the audience before recording } \\
\text { and record on the presenter's device so he } \\
\text { or she has control over the recording. }\end{array}$ \\
\hline $\begin{array}{l}\text { Conduct a postpresentation discussion } \\
\text { session: Make time for formal or informal } \\
\text { reflection and discussion among audience } \\
\text { members and speakers. }\end{array}$ & $\begin{array}{l}\text { Provides multiple perspectives on a session to } \\
\text { a targeted set of questions generated by } \\
\text { the presenter and audience }\end{array}$ & $\begin{array}{l}\text { Gather contact information to follow up after } \\
\text { the session. Set up end of session focus } \\
\text { group or postsession dinner. }\end{array}$ \\
\hline
\end{tabular}

aWe suggest these questions for a simple, yet informative postpresentation feed-up survey about your presentation: What did you find most interesting about this presentation? What, if anything, was unclear or were you confused about (a.k.a. muddiest point)? What is one thing that would improve this presentation? Similarly, to gather information for a feedback/feed-forward assessment, we recommend: What did you find most interesting about this work? What about this project needs improvement or clarification? What do you consider an important next step that this work might take?

structure, though they apply to the conference presentation setting as well.

An overarching goal of conferences is to help build a thriving, creative, inclusive, and accessible community. Being transparent about which equity strategies you are using and why you are using them may help to promote buy-in and encourage others to use similar strategies. By taking the above actions as presenters and being deliberate in our incorporation of equity and diversity strategies, we can help our professional communities to thrive, innovate, and grow.

\section{Challenge: Receiving Feedback}

Consider your last conference presentation: What did you take away from the presentation? Did you gather good ideas during the session? Were the questions and comments you received useful for advancing your work? If you were to present this work again, what changes might you make? In the classroom, assessment drives learning of content, concepts, and skills. At conferences, we, as presenters, take the role of instructor in teaching our peers (including members of our research field) about new findings and innovations. However, assessment at conferences differs from classroom assessment in important ways. First, at conferences, you are unlikely to present to the same audience multiple times; therefore, the focus of the assessment is purely formative-to determine whether the presentation accomplished its goals. This feedback can aid in your professional development toward being an effective communicator. Second, at conferences, you are speaking to a diverse group of colleagues who have varied expertise, and feedback from the audience will provide information that may improve your research. Indeed, conferences are a prime environment to draw on a diversity of expertise to identify relevant information, resources, and alternative interpretations of data. These charac- teristics of conferences give rise to three possible types of presentation assessments (Hattie and Timperley, 2007):

- Feed-up: assessment of the achievement of presentation goals: Did I achieve my goals as a presenter?

- Feed-back: assessment of whether progress toward project goals is being achieved: Is my disciplinary work or research progressing effectively?

- Feed-forward: input on which activities should be undertaken next: What are the most important next steps in this work for myself and my professional community?

Though a lot of feedback at conferences occurs in informal settings, you can take the initiative to incorporate assessment strategies into your presentation. Many of the simple classroom techniques described in the preceding sections, like polling the audience and hearing from multiple voices, support quick assessment of presentation outcomes (Angelo and Cross, 1993). In Table 3, we elaborate on possible assessment strategies and provide tips for gathering effective feedback during presentations.

Technology can assist in implementing assessment, and we predict that there will be many future technological innovations applicable to the conference setting. Live tweeting or backchanneling is occurring more frequently alongside presentations, with specific hashtags that allow audience members to initiate discussions and generate responses from people who are not even in the room (Wilkinson et al., 2015). After the presentation, you and your audience members can continue to share feedback and materials through email list servers and QR codes. Self-assessment by reviewing a video from the session can support both a better understanding of audience engagement and self-reflection (van Ginkel et al., 2015). There are benefits from gathering data from multiple assessment strategies, but as we 
will discuss in the next section, there are barriers that impact the number of recommended learning, equity, and assessment strategies you might chose to implement.

\section{NAVIGATING BARRIERS TO SCIENTIFIC PRESENTING}

Though we are strong advocates for a scientific presenting approach, there are several important barriers to consider. These challenges are similar to what is faced in the classroom, including time, space, professional culture, and audience/student expectations.

One of the most important barriers to consider is culture, as reflected in the following quote:

Ironically, the oral presentations are almost always presented as lectures, even when the topic of the talk is about how lecturing is not very effective! This illustrates how prevalent and influential the assumptions are about the expected norms of behavior and interaction at a scientific conference. Even biologists who have strong teaching identities and are well aware of more effective ways to present findings choose, for whatever reason (professional culture? professional identity?), not to employ evidence-based teaching and communication methods in the venue of a scientific conference. (Brownell and Tanner, 2012, p. 344)

As this quote suggests, professional identity and power structures exist within conference settings that may impact the use of scientific presenting strategies. Trainees early in their careers will be impacted by disciplinary conference norms and advisor expectations and should discuss incorporating new strategies with a trusted mentor. In addition, incorporating scientific presenting strategies can decrease your control as a presenter and may even invoke discomfort and threaten your or your audience's professional identities.

Balance between content delivery and active engagement presents another potential barrier. Some may be concerned that active learning takes time away from content delivery or that using inclusive practices compromises the clarity of a central message. Indeed, there is a trade-off between content and activity, and presenters have to balance presenting more results with time spent on active learning that allows the audience to interpret the results. We suggest that many of these difficulties can be solved by focusing on your goals and audience background, which will allow you to identify which content is critical and hone your presentation messaging to offer the maximum benefit to the audience. Remember that coverage of content does not ensure learning or understanding and that you can always refer the audience to additional content or clarifying materials by providing handouts or distributing weblinks to help them engage as independent learners.

Physical space and time may limit participants' interaction with you and one another. Try to view your presentation space in advance and consider how you will work within and possibly modify that space. For example, if you will present in a traditional lecture hall, choose active learning that can be completed by an individual or pairs instead of a group. By being aware of the timing, place in the conference program, and space allotted, you can identify appropriate activities and strategies that will fit your presentation and have a high impact. Available technology, support, and resources will also impact the activities and assessments you can implement and may alleviate some space and time challenges.
As novice scientific presenters dealing with the above barriers and challenges, "failures" or less than ideal attempts at scientific presenting are bound to occur. The important thing to remember is that presenting is a scientific process, and just as experiments rarely work perfectly the first time they are executed, so too does presenting in a new and exciting way. Just as in science, challenges and barriers can be overcome with time, iterations, and thoughtful reflection.

\section{STRUCTURING A CONFERENCE TO FACILITATE SCIENTIFIC PRESENTING}

Although presenters can opt to use backward design and incorporate scientific presenting strategies, they do not control other variables like the amount of time allotted to each speaker, the size or shape of the room they present in, or the technology available. These additional constraints are still important and may impact a presenter's ability to use audience-centered presentation methods. Conference organizers are in a powerful position to support presenters' ability to implement the described strategies and to provide the necessary logistical support to maximize the likelihood of success. Organizers often set topics, determine the schedule, book spaces, identify presenters, and help establish conference culture.

So how can conference organizers affect change that will promote active engagement and equity in conference presentations?

1. Use backward design for the conference as a whole. Just as presenters can use backward design to set their specific learning goals, conference organizers can set goals for the meeting as a whole to support the conference community.

2. Vary conference structures and formats based on the needs of the community. Conference presentation structures vary widely, but it is worth considering why certain session structures are used. To what extent does it serve the community to have back-to-back 10-minute talks for several hours? Many people will have the chance to present, but does the audience gain anything? Are there topics that would be better presented in a workshop format or a roundtable discussion? What other structures might benefit the conference community and their goals?

3. Choose a space that is conducive to active presentations or consider creative ways to use existing spaces. The spaces available for conferences are typically designed for lecture formats. However, organizers can seek out spaces that facilitate active presenting by choosing rooms with adaptable formats in which furniture can be moved to facilitate small-group discussions. They can also provide tips on how to work within existing spaces, such as encouraging participants to sit near the front of a lecture hall or auditorium.

4. Give explicit expectations to presenters. Organizers could inform presenters that active, engaging, evidence-based sessions are encouraged or expected. This will help cultivate the use of scientific presenting within the community.

5. Provide examples or support for presenters to aid in design of active learning, equity strategies, and assessment. Videos with examples of the described techniques, a quick reference guide, or access to experts within the field who would be willing to mentor presenters could be critical for supporting a conference culture that uses scientific presenting. For example, researchers at the University of Georgia 
have developed a repository of active-learning videos and instructions for instructors interested in developing these skills (REALISE-Repository for Envisioning Active-Learning Instruction in Science Education, https://seercenter.uga.edu/ realisevideos_howto).

6. Collect evidence about conference structure and use it to inform changes. Surveying audience members and presenters to better understand the benefits and challenges of particular session formats can help inform changes over multiple years. Organizers should coordinate these efforts with presenters so they are aware of what data will be collected and disseminated back to them.

\section{CONCLUSION}

Although scientific teaching has increasingly become standard practice for evidence-based teaching of science courses, there are potentially great benefits for transforming our oral presentations in science and science education by incorporating the rigor, critical thinking, and experimentation that are regularly employed within research. The strategies suggested in this paper can serve as a starting point for experimentation and evaluation of presentation and conference efficacy. Using scientific presentation strategies may expedite the advancement of fields by increasing engagement and learning at conference presentations. Equity strategies can increase inclusion and community building among members of our research areas, which will help research fields to grow and diversify. Finally, regularly incorporating assessment into our presentations should improve the quality and trajectory of research projects, further strengthening the field. Both individual presenters and conference organizers have a role to play in shifting conference culture to tackle the challenges presented in this paper. We urge you to consider your role in taking action.

\section{ACKNOWLEDGMENTS}

We thank Justin Hines, Jenny Knight, and Kimberly Tanner for thoughtful suggestions on early drafts of this article.

\section{REFERENCES}

Andrew, T. M., Leonard, M. J., Colgrove, C. A., \& Kalinowski, S. T. (2011). Active learning not associated with student learning in a random sample of college biology courses. CBE-Life Sciences Education, 10(4), 394-405.

Angelo, T. A., \& Cross, K. P. (1993). Classroom assessment techniques: A handbook for college teachers. San Francisco: Jossey-Bass.

Bassett-Jones, N. (2005). The paradox of diversity management, creativity and innovation. Creativity and Innovation Management, 14(2), 169-175.

Brownell, S. E., \& Tanner, K. D. (2012). Barriers to faculty pedagogical change: Lack of training, time, incentives, and ... tensions with professional identity? CBE-Life Sciences Education, 11(4), 339-346.

Carlson, M., \& Burdsall, T. (2014). In-progress sessions create a more inclusive and engaging regional conference. American Sociologist, 45, 177. doi: 10.1007/s12108-014-9220-2

Chi, M. T. H., \& Wylie, R. (2014). The ICAP framework: Linking cognitive engagement to active learning outcomes. Educational Psychologist, 49(4), 219-243.

Eddy, S. L., \& Hogan, K. A. (2014). Getting under the hood: How and for whom does increasing course structure work? CBE-Life Sciences Education, 13(3), 453-468.
Freeman, S., Eddy, S. L., McDonough, M., Smith, M. K., Okoroafor, N., Jordt, H., \& Wenderoth, M. P. (2014). Active learning increases student performance in science, engineering, and mathematics. Proceedings of the National Academy of Sciences USA, 111(23), 8410-8415.

Haak, D. C., HilleRisLambers, J., Pitre, E., \& Freeman, S. (2011). Increased structure and active learning reduce the achievement gap in introductory biology. Science, 332(6034), 1213-1216.

Hacker, K. (2013). Community-based participatory research. Los Angeles, CA: Sage.

Handelsman, J., Miller, S., \& Pfund, C. (2007). Scientific teaching. New York: Macmillan.

Hatch, J., Jensen, M., \& Moore, R. (2005). Manna from heaven or clickers from hell. Journal of College Science Teaching, 34(7), 36.

Hattie, J., \& Timperley, H. (2007). The power of feedback. Review of Educational Research, 77(1), 81-112

Kember, D., \& Leung, D. Y. (2005). The influence of active learning experiences on the development of graduate capabilities. Studies in Higher Education, 30(2), 155-170.

Kuh, G., Kinzie, J., Buckley, J., Bridges, B. K., \& Hayek, J. C. (2006). What matters to student success: A review of the literature (Commissioned Report for the National Symposium on Postsecondary Student Success: Spearheading a Dialog on Student Success. Retrieved July 3, 2017, from https://nces.ed.gov/npec/pdf/kuh_team_report.pdf

Langin, K. M. (2017). Tell me a story! A plea for more compelling conference presentations. The Condor, 119(2), 321-326.

McTighe, J., \& Thomas, R. S. (2003). Backward design for forward action. Educational Leadership, 60(5), 52-55.

Michael, J. (2006). Where's the evidence that active learning works? Advances in Physiology Education, 30(4), 159-167.

Miller, S., \& Tanner, K. D. (2015). A portal into biology education: An annotated list of commonly encountered terms. CBE-Life Sciences Education, 14(2), fe2.

Motschenbacher, H. (2017). Inclusion and foreign language education. ITLInternational Journal of Applied Linguistics, 167(2), 159-189.

National Research Council. (2000). How people learn: Brain, mind, experience, and school (expanded ed.). Washington, DC: National Academies Press. https://doi.org/10.17226/9853

Osborne, J. (2010). Arguing to learn in science: The role of collaborative, critical discourse. Science, 328(5977), 463-466.

Prince, M. (2004). Does active learning work? A review of the research. Journal of Engineering Education, 93(3), 223-231.

Richard, O. C., \& Shelor, R. M. (2002). Linking top management team age heterogeneity to firm performance: Juxtaposing two mid-range theories. International Journal of Human Resource Management, 13(6), 958-974.

Rossi, A. L., \& Lopez, E. J. (2017). Contextualizing competence: Language and LGBT-based competency in health care. Journal of Homosexuality. 64(10), 1330-1349.

Tanner, K. D. (2013). Structure matters: Twenty-one teaching strategies to promote student engagement and cultivate classroom equity. CBE-Life Sciences Education, 12(3), 322-331.

van Ginkel, S., Gulikers, J., Biemans, H., \& Mulder, M. (2015). Towards a set of design principles for developing oral presentation competence: A synthesis of research in higher education. Educational Research Review, 14, 62-80.

Walton, G. M., Cohen, G. L., Cwir, D., \& Spencer, S. J. (2012). Mere belonging The power of social connections. Journal of Personality and Social Psychology, 102(3), 513.

Wilkinson, S. E., Basto, M. Y., Perovic, G., Lawrentschuk, M., \& Murphy, D. G. (2015). The social media revolution is changing the conference experience: Analytics and trends from eight international meetings. BJU International, 115(5), 839-846. doi: 10.1111/bju.12910

Winter-Collins, A., \& McDaniel, A. M. (2000). Sense of belonging and new graduate job satisfaction. Journal for Nurses in Professional Development, 16(3), 103-111. 